\title{
AFFECTIVE STATES AND PERFORMANCE OUTCOMES - THE FINDINGS OF PRELIMINARY RESEARCH INVOLVING PENTATHLETES
}

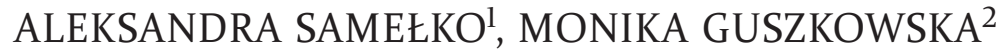 \\ Józef Pitsudski University of Physical Education in Warsaw, Faculty of Physical Education, \\ Doctoral Studies ${ }^{1}$, Faculty of Tourism and Recreation, Department of Recreation Methodology ${ }^{2}$ \\ Mailing address: Aleksandra Samełko, Józef Piłsudski University of Physical Education, 34 Marymoncka \\ Street, 00-968 Warszawa, tel.: +48 509891441, fax: +48 22 8651080, e-mail: al.samelko@gmail.com
}

\begin{abstract}
Introduction. The aim of this article is to discuss the relationship between affective states experienced by athletes and the outcome of their performance. The article presents the findings of a pilot study which made it possible to determine the relationship between the emotional states, mood, and level of stress of a group of pentathletes and the outcomes they achieved in a sports competition. Material and methods. The study involved 12 senior modern pentathletes, including 7 male and 5 female athletes. The following standard psychology questionnaires were used in the study: the 10-item Perceived Stress Scale (PSS-10), the Positive and Negative Affect Schedule (PANAS), and the Profile of Mood State (POMS). Performance was assessed based on the number of points achieved by the pentathletes in particular events in the pentathlon, which are held according to the rules set by the International Modern Pentathlon Union (UIPM). Results. The findings of the study confirmed that there was a correlation between the athletes' mood and emotions and the outcome of their performance. The level of stress strongly negatively correlated with both the outcome they expected to achieve and the one they actually achieved for the combined event (running and shooting). For this event a relationship was also found between the athletes' affective states and their outcomes: in running and shooting there was a positive and statistically significant correlation between the level of positive emotions and anger and the results achieved. However, friendliness, one of the other affective state variables that were measured, correlated negatively with the outcomes of the athletes' performance. Conclusions. In the group of pentathletes who participated in the study, a high level of anger was associated with better outcomes, and a high level of friendliness had an adverse effect on the results achieved. The findings of the current study confirm that there is a relationship between affective states and performance outcomes, but the findings do not correspond with Morgan's iceberg profile.
\end{abstract}

Key words: performance outcome, mood, emotion, stress

\section{Introduction}

Athletes who take part in the most prestigious sports competitions do not only undergo physical, technical, and tactical training but also receive psychological preparation. Since in the past few years competitors in various disciplines have demonstrated a similar level of sports skills, psychological preparation has played an increasing role in determining the outcome of these events [1]. This preparation should include, among others, coping with stress and managing affective states such as mood and emotions. Emotions are short-lasting but intensive states which are related to a particular object and are caused by particular events [2]. Moods, on the other hand, last longer, are less intensive than emotions, and usually cannot be traced to a particular source [3].

During the immediate pre-competition and competition periods, athletes tend to feel strong emotions having to do with stress. Emotions experienced in these periods cause a higher than usual level of arousal, which can be either desirable or excessive and stimulate athletes to perform exceptionally well or poorly. The latter is particularly frequent when athletes feel they are under heavy pressure [4]. Stress and the emotions that accompany it depend on the importance of the competition as well as the athletes' experience, fitness level, motivation, aspirations, and temperament [5]. In addition, athletes may be affect- ed by external stressors which do not have to do with practising sports.

Three pre-competition states which differ in terms of the level of the athlete's arousal are mentioned in the literature. The state that is the most desirable before the competition is the state of (optimal) arousal, or mobilisation, as athletes who are in this state are usually the most effective. This state is characterised by an increased respiration rate, sweating, the willingness to take part in the competition, and a positive attitude. One of the non-optimal states is anxiety, which causes ineffective performance and is characterised by mood swings, absent-mindedness, and nervousness. However, an even more undesirable state is apathy, which is accompanied by drowsiness and a reluctance to participate in the competition [5].

The most widely known research into the relationship between affective states and the outcomes of sports performance was conducted by Morgan in the 1970s and 1980s [6]. The results led to the development of the so-called "iceberg profile", which describes the mood state of athletes who perform well in prestigious competitions as characterised by a low level of negative affective states (tension, depression, anger, fatigue, and confusion) and a high level of vigour.

The studies of several other authors have since confirmed that there is a relationship between performance and affective states, especially mood $[7,8]$. A meta-analysis of the available 
research conducted by Lane and Beedie [9] has shown that mood profiles make it possible to predict the outcome of an athlete's performance in a competition regardless of their level of achievement. Not all studies related to this issue, however, have provided evidence confirming that there is a relationship between affective states and sports performance [10]. Moreover, this relationship tends to differ depending on the dynamics of the emotions that are experienced, the athlete's personality, the specificity of the sports discipline, and the conditions in which the competition is held [11]. The findings of some studies have even shown that a high level of stress experienced before the competition can mobilise the athlete by releasing more energy [12].

The results of recently conducted research suggest that reducing the level of negative mood states does not guarantee that an athlete will be successful. Comparative analyses of more and less successful cross-country skiers have shown that athletes who rank first in competitions do not only exhibit a higher level of vigour than less effective skiers but also a higher level of anger and tension [13].

In light of the above, the model developed by Morgan [6] more than 35 years ago may have become outdated and should be verified by current research. Thus, the aim of this pilot study was to determine the relationship between emotional states, mood, and an increased level of stress and the outcomes achieved by pentathletes in a sports competition.

\section{Material and methods}

The study involved 12 senior pentathletes, including 5 women and 7 men. The mean age of the group was 20.9 years $(\mathrm{SD}=2.097)$.

Two standard psychology questionnaires with established and appropriate psychometric properties were applied. Mood was assessed using the Profile of Mood State (POMS) questionnaire which offers scales for seven affective states (tension, depression, anger, fatigue, confusion, vigour, and friendliness) developed by McNair, Lorr, and Droppleman [14]. A Polish adaptation of the questionnaire designed by Dudek and Koniarek [15] was used. The emotional state the subjects were experiencing immediately before taking part in the competition was measured using a Polish adaptation (SUPIN) of the Positive and Negative Affect Schedule (PANAS) instrument by Watson and Clark [16]. Stress, which was expected to be increased in the final hours before the competition, was assessed using the 10-item Perceived Stress Scale (PSS-10) designed by Kamarck, Mermelstein, and Cohen [17]. A Polish version of the scale created by Juczyński and Ogińska-Bulik [18] was applied.

The study was conducted during the Polish Modern Pentathlon Championships in August 2014. The subjects were asked to complete the questionnaires concerning their affective state and level of stress an hour or less before taking part in each of the events in the competition. The pentathletes were also asked to provide information concerning their personal best performances and the outcomes they were expecting to achieve in the competition. Finally, the number of points the athletes received in the each of the disciplines (swimming, fencing, horse riding, and cross-country running combined with shooting) were recorded.

In order to establish correlations between the data, the Pearson product-moment correlation coefficient was calculated using IBM SPSS (v. 22).

\section{Results}

There was a strong correlation between increased stress and the expected $(\mathrm{r}=-0.920 ; \mathrm{p}<0.001)$ and achieved $(\mathrm{r}=-0.925$; $\mathrm{p}<0.001$ ) outcomes only for the combined event, and, as predicted, this correlation was negative.

Table 1 shows how the pentathletes' affective states correlated with the outcome they were expecting to achieve and the one they actually achieved as well as the statistical significance of these correlations. Due to the small number of subjects involved in the study, both statistically significant correlations and those demonstrating a trend towards statistical significance are provided.

Table 1. Correlations between the affective state variables and the scores obtained in particular disciplines in the pentathlon

\begin{tabular}{|c|c|c|c|}
\hline Discipline & $\begin{array}{c}\text { Mood/emotional } \\
\text { state variable }\end{array}$ & $\begin{array}{l}\text { Correlation with } \\
\text { expected outcome }\end{array}$ & $\begin{array}{l}\text { Correlation with } \\
\text { actual outcome }\end{array}$ \\
\hline Swimming & Friendliness & $\begin{array}{l}r=-0.592 \\
p=0.042\end{array}$ & \\
\hline Horse riding & Vigour & $\begin{array}{l}r=0.528 \\
p=0.078\end{array}$ & \\
\hline Fencing & Anger & $\begin{array}{l}r=0.574 \\
p=0.051\end{array}$ & \\
\hline \multirow{4}{*}{$\begin{array}{l}\text { Combined } \\
\text { discipline } \\
\text { (running and } \\
\text { shooting) }\end{array}$} & $\begin{array}{l}\text { Positive } \\
\text { emotions }\end{array}$ & $\begin{array}{l}r=0.547 \\
p=0.066\end{array}$ & $\begin{array}{l}r=0.501 \\
p=0.097\end{array}$ \\
\hline & $\begin{array}{l}\text { Negative } \\
\text { emotions }\end{array}$ & $\begin{array}{c}r=-0.581 \\
r=0.048\end{array}$ & $\begin{array}{l}r=-0.583 \\
p=0.047\end{array}$ \\
\hline & Friendliness & $\begin{array}{l}r=-0.639 \\
p=0.025\end{array}$ & $\begin{array}{l}r=-0.590 \\
p=0.043\end{array}$ \\
\hline & Anger & $\begin{array}{l}r=0.613 \\
p=0.034\end{array}$ & $\begin{array}{l}r=0.619 \\
p=0.032\end{array}$ \\
\hline
\end{tabular}

${ }^{*} \mathrm{r}$ - Pearson's correlation coefficient, $\mathrm{p}$ - level of statistical significance.

Correlations between the affective state of the athletes and their outcome were found only for the combined event (crosscountry running and shooting). The correlations were the stronger, the higher the level of positive emotions and anger was and the lower the level of negative emotions and friendliness was. Similar correlations were found between the athletes' affective state and the results they were expecting to achieve.

For the other disciplines, only correlations between affective states and the expected outcome were found. The score the athletes were expecting to achieve was the higher, the higher their level of vigour (before horse riding) and anger (before fencing) was and the lower their level of friendliness (before swimming) was.

Figure 1 depicts the trends in the data collected for the mood state variables of anger and friendliness and the total scores achieved by the athletes in all the disciplines. The $\mathrm{x}$-axis represents the scores of the subjects arranged from the highest score (no. 1) to the lowest one (no. 12). The y-axis represents the subjects' level of anger and friendliness. The trend lines are sloping in the opposite direction, starting from the data collected for the more effective athletes who experienced a higher level of anger and lower level of friendliness to those obtained for the 
less effective athletes who experienced a higher level of friendliness and lower level of anger.

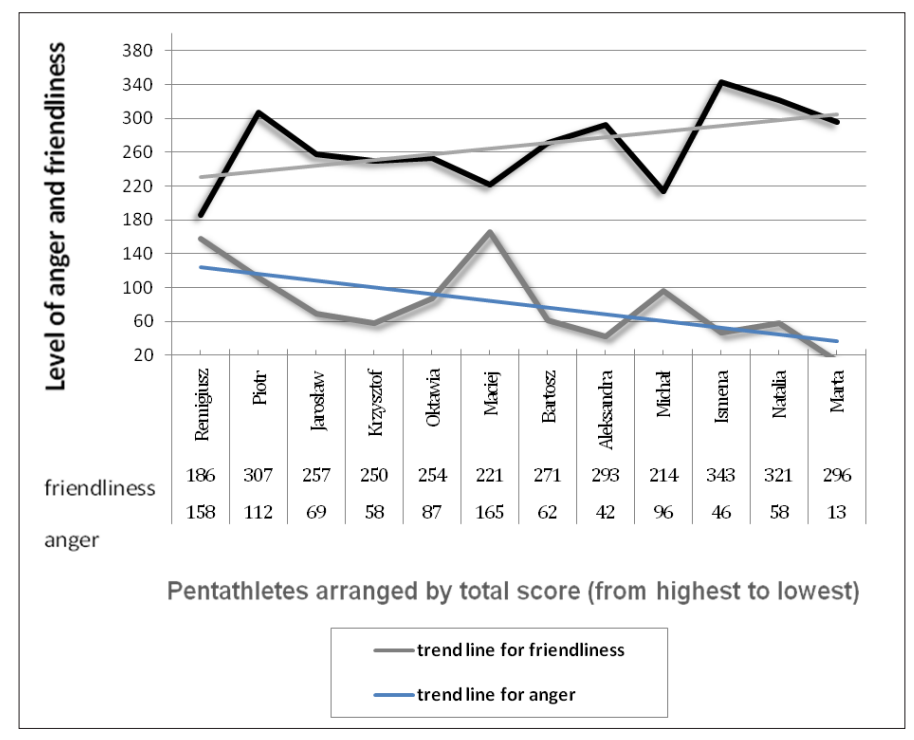

Figure 1. Level of anger and friendliness and the outcome achieved by the subjects

\section{Discussion}

Morgan [6] found that superior outcomes of sports performance are accompanied by an increased level of vigour and a low level of negative emotional states. Other authors, however, have observed that the iceberg profile developed for athletes achieving high outcomes is not universal and that it simplifies the relationship between the athlete's affective state and their outcome [10]. Studies involving various athletes in individual and team sports have confirmed that there is a correlation between positive mood and the outcomes they achieve: positive emotions are associated with better outcomes and negative ones with worse outcomes [19]. Analyses of mood states conducted during the training period have also revealed a positive correlation between positive mood and the athlete's attitude towards training and ability to handle training loads [20]. According to some authors [21], a better mood is linked with a higher level of motivation for undertaking effort.

The results of the pilot study suggest that the relationships between affective states and performance outcomes may be different from those postulated by Morgan [6]. Better outcomes were achieved not by athletes with a higher level of vigour but by those who felt anger. It was also found that there was a negative correlation between the pentathletes' level of friendliness and their performance outcome. It is worth noting that although analyses conducted by other authors have shown that athletes who have better outcomes may experience a higher level of anger [22, 23], it has been stated that this is only possible when other negative POMS variables are low [24].

The correlations observed in this research were most probably directly related to the athletes' participation in the competition. A high level of anger experienced before the competition may be a sign that the athlete is ready and determined to compete with their opponents. A low level of friendliness is an- other symptom of being oriented towards competing with other athletes. Coaches who tend to intuitively stimulate athletes to feel this type of anger may thus be putting them in an optimal mental state before the competition, which helps them achieve better results.

The findings of previous studies which made used of the POMS scale [24] indicate that depression is a feeling which is worth paying particular attention to. When its level is elevated, all negative emotional states tend to become exacerbated and have an adverse impact on the outcome achieved by athletes. Little research, however, is available when it comes to the level of friendliness experienced by athletes and its impact on their outcome.

Nowadays, there is a tendency for researchers to analyse the change in the affective state profiles of particular athletes and their correlation with performance outcomes rather than seek universal correlations [25]. A relevant factor that may have an impact in this regard is an individual athlete's attitude towards the stress they experience in connection with the competition which is stressed by Asztalos et al. [26]. Repeated assessments of affective states experienced before the competition can make it possible to develop a profile for a given athlete that is conducive to achieving superior results. Observing the athlete, their experience, and their affective states offers considerable benefits, even if the relationship between the affective state and the performance outcome is not always the same. Every athlete's emotional reaction is unique, and high outcomes can be achieved with different emotional profiles. Mental training should include teaching the athlete how to regulate their emotions and generate an optimal affective profile in the immediate pre-competition period. Monitoring the athlete's mood is thus essential step in helping them consciously manage their affective states, and, as a result, achieve better results.

\section{Results and conclusions}

The findings of the study suggest that modern pentathletes who achieve better outcomes experience a heightened level of anger and a lower level of friendliness immediately before participating in particular events in the competition. In the group examined in this study, the points gained in the combined event strongly negatively correlated with the level of stress. It is for this event, which was the final event in the entire competition, that the strongest correlations were found between the athletes' emotional states and their outcome. It may be assumed that competing for the final score and being able to observe the opponents in the final part of the competition increases the level of emotions experienced and affects the final result.

It should be borne in mind that the current study is a pilot study. Further research aimed at determining the relationship between the results obtained in the consecutive events in a competition and the affective states experience by athletes before and during the competition is needed. Monitoring the emotional states of modern pentathletes can yield particularly interesting information in this regard due to the fact that they engage in different disciplines which vary in terms of their physical and psychological requirements.

The current study has confirmed that there are correlations between affective states and the outcomes of the performance of pentathletes. However, the findings of the study do not correspond with Morgan's iceberg profile. The subjects who experienced a high level of anger performed better, and those who had high level of friendliness performed worse. 
We recommend that mood and emotions experienced both during training and competitions should be monitored by the athletes' coaches. Similarly to endurance, speed, flexibility, and coordination, affective states also have a direct impact on the outcomes achieved by athletes.

\section{Acknowledgements}

The research was conducted under a grant from the Józef Piłsudski University of Physical Education in Warsaw - DM. 33 - financed by the Ministry of Science and Higher Education.

\section{Literature}

1. Karageorghis C.I., Terry P.C. (2014). Inside sport psychology. Zielonka: Wydawnictwo Inne Spacery. [in Polish]

2. Davidson R.J. (1998). On emotion, mood, and related affective constructs. In P. Ekman, R.K. Davidson (eds), The nature of emotion: Fundamental questions (pp. 50-54). Gdańsk: Gdańskie Wydawnictwo Psychologiczne. [in Polish]

3. Strelau J. (2007). Psychology. An academic textbook. Gdańsk: Gdańskie Wydawnictwo Psychologiczne. [in Polish]

4. Kłodecka-Różalska J. (1993). Coping with stress. Warszawa: Wyd. RCMSKFiS i IS, Biblioteka Trenera. [in Polish]

5. Gracz J., Sankowski T. (1995). Psychology of sport. Poznań: AWF. [in Polish]

6. Morgan W.P. (1980). Test of champions: The iceberg profile. Psychology Today 14, 92-108.

7. Raglin J.S., Morgan W.P., Luchsinger A.E. (1990). Mood and self-motivation in successful and unsuccessful female rowers. Medicine and Science in Sports and Exercise 6, 849853.

8. Lane A.M., Terry P.C., Beedie C.J., Curry D.A., Clark N. (2001). Mood and performance: test of a conceptual model with a focus on depressed mood. Psychology of Sport and Exercise 2, 157-172.

9. Beedie C.J., Terry P.C., Lane A.M. (2000). The Profile of Mood States and athletic performance: Two-meta analyses. Journal of Applied Sport Psychology 12(1), 49-68.

10. Jarvis M. (2003). Psychology of sport. Gdańsk: Gdańskie Wydawnictwo Psychologiczne. [in Polish]

11. Lupul-Nawrocka A. (2005). Emotions and their influence on the performance of a young athlete in competitions. Sport wyczynowy 1-2, 481-482.

12. Meijen C., Jones M., Sheffield D., McCarthy P. (2014). Challenge and threat states: Cardiovascular, affective, and cognitive responses to a sports-related speech task. Motivation and Emotion 38(2), 252-262.
13. Cockerill I.M., Nevill A.M., Lyons N. (1991). Modelling mood states in athletic performance. Journal of Sports Sciences 9, 205-212.

14. McNair D.M., Lorr M., Droppelman L.F. (1971). Manual for the Profile of Mood States. San Diego: Educational and Industrial Testing Service.

15. Dudek B., Koniarek J. (1987). An adaptation of the Profile of Mood States (POMS) test by D.M. McNaira, M. Lorra, and L.F. Droppleman. Przegląd Psychologiczny 3, 753-762. [in Polish]

16. Brzozowski P. (2010). Positive and Negative Affect Schedule. SUPIN: a Polish adaptation of the PANAS scale by David Watson and Anna Clark. Warszawa: Polskie Towarzystwo Psychologiczne. [in Polish]

17. Cohen S., Kamarck T., Mermelstein R. (1983). A global measure of perceived stress. Journal of Health and Social Behavior 24, 385-396.

18. Juczyński Z., Ogińska-Bulik N. (2009). Tools for measuring stress and stress management. Warszawa: Polskie Towarzystwo Psychologiczne. [in Polish]

19. Friesen A.P., Lane A.M., Devonport T.J., Sellars Ch.N., Stanley D.N., Beedie C.J. (2013). Emotion in sport: considering interpersonal regulation strategies. International Review of Sport and Exercise Psychology 13(6), 139-154.

20. Brandt R., Viana M.S., Segato L., Kretzer F.L., Carvalho T., Andrade A. (2011). Relationships between mood states and sport performance in high level sailors. Psicologia: Teoria e Prática 13(1), 117-130. [in Portuguese]

21. Ekici S. (2011). The effect of positive and negative mood on motivation to succeed of elite athletes. International Journal of Human Sciences 8(2), 945-962.

22. Carter L., Sachs M. (2012). In the mood: flow, mood, and the marathon. Marathon and Beyond 16(5), 68-79.

23. Borek-Chudek D. (2011). Emotional states and the performance of badminton players. In O. Gorbaniuk, B. Kostrubiec-Wojtachnio, D. Musiał, M. Wiechetek, A. Błachnio, A. Przepiórka (eds), Psychology studies at the John Paul II Catholic University of Lublin (KUL). Vol. 17 (pp. 109-132). Lublin: Wyd. KUL. [in Polish]

24. Lane A.M., Terry P.C., Beedie C.J., Curry D.A., Stevens M. (2004). Mood and concentration grid performance: Effects of depressed mood. Psychology of Sport and Exercise 2, 133145.

25. Lane A.M., Terry P.C. (2000). The nature of mood: development of a conceptual model with a focus on depression. Journal of Applied Sport Psychology 12, 16-33.

26. Asztalos M., Wijndaele K., Bourdeaudhuij I., Philippaerts R., Matton L., Duvigneaud N. et al. (2012). Sport participation and stress among women and men. Psychology of Sport and Exercise 13, 466-483.

Submitted: October 30, 2015

Accepted: November 27, 2015 